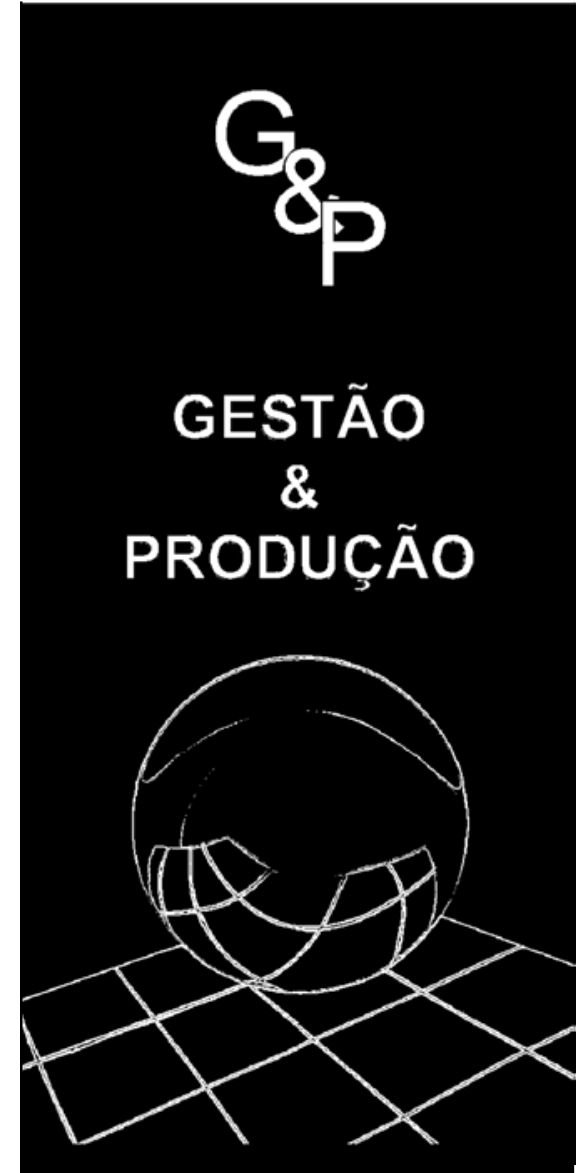

v.6, n.1, p. 51-60, abr. 1999

\title{
AVALIAÇÃO DO IMPACTO DA \\ REENGENHARIA NAS GRANDES EMPRESAS DO BRASIL
}

\author{
Flávio César F. Fernandes \\ Rossano Margotto Bertollo \\ Departamento de Engenharia de Produção - UFSCar \\ Via Washington Luís, Km 235 \\ CEP 13565-905 - São Carlos - SP \\ Fax: (016) 260-8240 \\ E-mail: dfcf@power.ufscar.br
}

\section{Resumo}

Este artigo analisa a implantação dos processos de Reengenharia em empresas no Brasil. É um estudo estatístico para revelar o que está ocorrendo, em termos de mudanças radicais, nas organizações brasileiras. Em termos gerais, a metodologia utilizada é a mesma que a de um estudo similar realizado em empresas norte-americanas. Assim sendo, além de tirarmos interessantes e importantes conclusões sobre a situação brasileira, foi também possivel comparar os principais resultados com o caso norte-americano.

Palavras-chave: reengenharia, reconstrução de negócios, processos de negócios.

“NADA É PERMANENTE, EXCETO AS MUDANÇAS” (Heraclitus - 500 A.C.)

\section{Introdução}

耳 ste artigo fundamenta-se teoricamente em - artigos e livros publicados relacionados com Reengenharia de Processos de Negócio.

No coração da Reengenharia encontra-se a noção de pensamento descontínuo, isto é, a preocupação com a mudança de uma situação para outra de forma radical, que se baseia em reconhecer e esquecer as velhas regras e premissas fundamentais que regulam as operações (BRANDT \& BYRNE, 1993).

Uma Reengenharia dos Processos de Negócio (R.P.N. ou B.P.R.) não pode ser planejada 
meticulosamente e realizada em pequenos e cautelosos passos, é uma proposição "tudo ou nada" com um resultado incerto (HAMMER \& CHAMPY, 1990).

A grande preocupação em transformar os cenários atuais nos quais as empresas estão enquadradas possui causas que só podem ser entendidas realizando-se uma análise histórica da evolução dos modelos de produção industrial. Os processos atuais não acompanharam as recentes mudanças ocorridas nas áreas de tecnologia, demografia e objetivos do negócio.

Esse modelo de produção atual, que compreende objetivos, tipo de organização, e tecnologia empregada, vem de longa data e iniciou-se com a Revolução Industrial na qual havia especializações do trabalho e economia de escala com produtos fabricados basicamente em série. Como a produção não atendia às demandas, tudo que era produzido era vendido sem problemas, e a ineficiência de gestão das empresas ficava mascarada pelos bons resultados obtidos.

Em seguida, no período pós-Segunda Guerra Mundial, a maior preocupação era o crescimento rápido. Com isso, os negócios se concentraram em redução de custo, crescimento rápido e grande controle sobre a produção.

Hoje, com a mudança nos cenários econômi$\cos$, a concorrência tornou-se um fator relevante, e as empresas devem ser competitivas para poderem oferecer produtos de qualidade, a preços competitivos e com um bom atendimento ao cliente (DAVENPORT, 1994).

Esse novo modelo exige que as empresas possuam uma visão do negócio como um todo e, principalmente, uma grande flexibilidade e adaptabilidade dos seus processos e negócios. Isso esbarra em estruturas departamentais e hierárquicas que restringem as informações ao topo das organizações, centralizadas nas altas gerências que acabam não utilizando essas informações de forma tão expressiva (SAVIANI, 1994).

O objetivo deste artigo é avaliar o impacto da Reengenharia em grandes empresas brasileiras. Em termos gerais, a metodologia utilizada foi a mesma do artigo "Empirically Assessing the
BPR Impact on Manufacturing Firms" de GUIMARAES \& BOND (1996), o qual avalia o impacto da Reengenharia nas empresas norteamericanas. A metodologia consistiu em: definir a amostra, fazer o levantamento do endereço de contato com as empresas da amostra por meio de um banco de dados, elaborar o questionário (já que no artigo de GUIMARÃES \& BOND (1996) ele foi omitido) e, finalmente, analisar as respostas dos questionários devolvidos. Fazemos também algumas comparações entre os resultados dos casos brasileiro e norteamericano.

\section{Tecnologia de Informação e Reengenharia}

$\mathbf{E}_{\text {importante analisarmos a Tecnologia da }}$ Informação (TI), que se constitui no principal alicerce da maioria dos processos de Reengenharia (GROVER et al., 1993). É formado pelas novas tecnologias baseadas em hardware e software de computadores que ajudam a aumentar a velocidade e a capacidade de transferência de informações. Como exemplo, podem ser citados os bancos de dados, o fax, as planilhas de cálculo, o código de barras etc.

DAVENPORT \& SHORT (1990) fazem a seguinte observação: "Os mais bem sucedidos usuários da tecnologia da informação parecem ter criado a Reengenharia de processos sem ter necessariamente consciência disso."

A maioria dos processos foi criada em épocas anteriores ao advento do computador como ferramenta necessária às aplicações das empresas. Graças a isso, sempre há a oportunidade de se implementar sistemas de informação baseados em computadores na gestão e execução dos processos.

Uma conseqüência desse fato é bastante notada nos processos que começam a utilizar o computador como ferramenta de trabalho. A grande maioria deles não foi projetada para poder um dia utilizar recursos computacionais e isso faz com que a aplicação seja superficial ou mesmo não traga resultados satisfatórios em termos econômicos. 
Assim, estudos revelam que, em geral, a tecnologia da informação aumenta a produção e reduz custos mas não aumenta a produtividade e a conseqüente lucratividade das empresas, pois os gastos adicionais não são compensados por aumento de produtividade (relação entre output e input). O que isso significa?

Primeiramente, para qualquer implantação deve-se investir em hardware, software e pessoal especializado para trabalhar ou treinar os envolvidos. O que acontece é que a redução de custos obtida pode não ser suficiente para justificar o investimento na nova tecnologia. Com isso há uma aceleração pura e simples do processo sem que melhorias substanciais sejam notadas.

Os processos antigos ao serem automatizados, na maioria das vezes não produzem resultados muito satisfatórios, pois suas estruturas são limitantes para melhorias no desempenho.

Um bom exemplo disso é o setor de serviços nos EEUU, que detêm $85 \%$ da TI instalada e contou com um discreto aumento de $0,8 \%$ na produtividade desde 1982 (DAVENPORT, 1994).

Dessa situação concluímos que as empresas utilizam a TI para automatizar processos atrasados. Em vez disso, como prega a Reengenharia, deve-se olhar para a TI como uma oportunidade (habilitador de mudança) para se realizar as tarefas (integradas ao processo) de forma diferente.

Graças a essa confusão dos implantadores da TI, os investimentos pesados em tecnologia de informação têm derivado resultados desapontadores, justamente porque há uma tendência a usar a tecnologia para automatizar velhas formas de realizar tarefas. Isso deixa os processos existentes intactos e usa computadores apenas para acelerá-los. A maioria dos processos, porém, são provenientes de diferentes ambientes competitivos, anteriores ao advento do computador. Esses processos são guiados para a eficiência e controle, enquanto as novas exigências de inovação, flexibilidade, velocidade, serviço e qualidade têm de se adequar a esses velhos processos (HAMMER, 1990).

Em sua essência, o que a Reengenharia faz é agrupar uma série de atividades e eliminar outras que não agregam valor, de modo que cada agrupamento de atividades seja realizado pelo menor número possível de servidores (de preferência, por um único servidor). Isso está sendo possível graças à Tecnologia de Informação em que o emprego de software e hardware computacionais acabam mudando a forma de organizar e controlar o trabalho.

\section{A Amostragem e o Banco de Dados}

$\mathrm{E}$ sta parte do estudo é de vital importância para a qualidade dos resultados obtidos, pois definindo-se as entidades que podem ser estudadas, supõe-se que estas irão retratar a realidade em questão. O comportamento das entidades pertencentes à amostra será estendido para todas as outras que possuam as mesmas características estruturais.

A amostra deste estudo foi, da mesma forma que o estudo de GUIMARAES \& BOND (1996), composto por grandes empresas. A razão é simples: as grandes empresas são as que mais têm se interessado pelos processos de Reengenharia, já que o próprio processo de Reengenharia ocorre predominantemente em empresas que possuam pelo menos algum nível de estrutura estabelecida, com processos de decisão mais complexos e que representam uma boa oportunidade para a aplicação da Reengenharia. A classificação das empresas como grandes ou pequenas se dá pelo seu faturamento.

Como banco de dados, foi utilizado o levantamento realizado anualmente pela empresa Exame, publicado na edição especial "Exame Melhores e Maiores". Ela traz as quinhentas maiores empresas do Brasil classificadas em ordem de faturamento.

Contudo, essa edição não possui o endereço para contato com essas empresas. Para obter essa informação, consultou-se o banco de dados da Telesoft Informática que possuía mais de 1000 empresas brasileiras. Com o cruzamento de ambos os dados, conseguiu-se o endereço de 239 empresas, independentemente da sua colocação no ranking. 


\section{A Formulação do Questionário}

$\mathrm{O}$ questionário utilizado foi elaborado com base nas tabelas do artigo de GUIMARAES \& BOND (1996), tomando o cuidado de selecionar o que era importante para o estudo proposto e adequar as proposições à realidade do Brasil.

A escala utilizada foi a seguinte:

\section{1. muito baixo}

2. baixo

3. médio

4. alto

5. muito alto

As perguntas sempre eram direcionadas para apresentarem esse tipo de resposta. Isso facilitou o preenchimento do questionário bem como a análise como um todo.

Juntamente com o questionário, foi enviada uma carta de apresentação, que serviu para: apresentar os autores da pesquisa, explicar ao entrevistado qual o intuito da pesquisa, mostrar a preocupação de não revelar qualquer dado em particular, deixar claro algum conceito e estabelecer o compromisso de enviar os principais resultados da pesquisa àqueles que respondessem o questionário.

\section{Resultados}

$\Delta \mathrm{s}$ respostas que foram retornadas corresApondem ao quadro representado pela Tabela 1 .

A porcentagem de questionários respondidos supera a maioria das pesquisas realizadas por meio de questionários e, em parte, isso se deve ao cuidado que se teve em prepará-lo seguindo as recomendações gerais de MUCCHIELLI (1979), entre elas, o tamanho recomendável do questionário. Vale observar que, embora não tenha sido pedido enfaticamente que a empresa devolvesse o questionário no caso de não ter realizado Reengenharia, obtivemos uma porcentagem significativa de empresas nesse caso. Certamente, a porcentagem real é ainda maior do que $27,12 \%$.
Outra estatística obtida inicialmente foi a divisão das empresas que responderam ao questionário e que fizeram Reengenharia por ramo de atuação (Tabela 2). O ramo preponderante é o metal-mecânico.

As respostas foram tratadas estatisticamente, calculando-se a média e o desvio padrão para cada pergunta. As tabelas abaixo apresentadas resumem os resultados mais importantes que mostram alguma tendência ou característica da amostra estudada.

Nas tabelas, as perguntas com respostas não significativas foram excluídas de modo a facilitar a visualização dos pontos importantes. Isso explica a descontinuidade na numeração das alternativas de cada pergunta nas Tabelas 4 a 9 . Os próprios títulos das tabelas contemplam o conteúdo das perguntas.

Pela pergunta da Tabela 3, tenta-se descobrir quais os setores da empresa mais atingidos pelo processo de Reengenharia. Dessa análise, têm destaque as mudanças na gestão de recursos humanos, na gestão da qualidade, no projeto e desenvolvimento do produto e em compras. Vale destacar que, com a globalização, várias multinacionais adquiriram empresas nacionais $\mathrm{e}$ desativaram ou reduziram as atividades dos departamentos de projeto e desenvolvimento do produto. Esse fato é compatível com o alto valor do desvio padrão (1,264: o maior da Tabela 3) para o setor de projeto e desenvolvimento do produto: nas empresas em que isso ocorreu o impacto foi alto ou muito alto, e naquelas em que isso não ocorreu o impacto não foi sequer alto.

Na pergunta da Tabela 4, tenta-se descobrir quais os principais objetivos dos processos estudados. A pergunta é direcionada para o planejamento da Reengenharia, pois é nele que as metas são estabelecidas. A lista completa de 14 possíveis objetivos pode ser encontrada no artigo de GUIMARAES \& BOND (1996); na Tabela 4 apenas colocamos os objetivos mais significativos (foram omitidos os objetivos 1, 3, 7, 12, 13 e 14) para o caso brasileiro. Em outras tabelas em que a numeração das possíveis alternativas não estiverem completas, vale esse último 
Tabela 1 - Respostas recebidas e sua distribuição.

\begin{tabular}{|c|c|c|}
\hline & Quantidade & Porcentagem \\
\hline Respostas recebidas & 59 & $26,46 \%$ (59 em 223) \\
Fez Reengenharia & 43 & $72,88 \%$ (43 em 59) \\
Não fez Reengenharia & 16 & $27,12 \%(16 \mathrm{em} \mathrm{59)}$ \\
Voltaram (endereço errado) & 16 & $6,69 \%$ (16 em 239) \\
\hline
\end{tabular}

Tabela 2 - Respostas recebidas e sua distribuição por ramos da indústria.

\begin{tabular}{|c|c|c|c|c|}
\hline Ramo & Metal-Mecânico & Químico & Eletroeletrônico & Serviços \\
\hline $\mathbf{N}^{\mathbf{0}}$ de Empresas & 18 & 13 & 8 & 4 \\
\hline Porcentagem & $41,9 \%$ & $30,2 \%$ & $18,6 \%$ & $9,3 \%$ \\
\hline
\end{tabular}

Tabela 3 - Grau de mudança que a Reengenharia provocou na empresa relacionada com os seguintes processos.

\begin{tabular}{|l|c|c|}
\hline & Média & $\sigma$ \\
\hline 1. serviço ao cliente & 3,310 & 0,975 \\
\hline 2. vendas & 3,300 & 1,091 \\
\hline 3. pagamento de contas & 2,976 & 1,037 \\
\hline 4. compras & 3,400 & 1,003 \\
\hline 5. projeto e desenvolvimento de produto & 3,415 & 1,264 \\
\hline 6. distribuição & 2,950 & 0,959 \\
\hline 7. administração de estoques & 3,256 & 0,978 \\
\hline 8. gestão da qualidade & 3,452 & 1,194 \\
\hline 9. planejamento da produção & 3,357 & 1,055 \\
\hline 10. gestão de recursos humanos & 3,549 & 1,213 \\
\hline
\end{tabular}

$\sigma$ - desvio padrão

comentário: só listamos as alternativas mais significativas para o caso brasileiro de modo a facilitar a visualização dos pontos importantes.

Pela Tabela 4, as respostas retratam a atual situação da economia brasileira. As empresas querem e precisam mudar seus processos principalmente para reduzir custos, de modo a aumentar a produtividade e a competitividade da empresa.

Essa situação possui respostas com valores menores comparados com a pesquisa de GUIMARAES \& BOND (1996), realizada no âmbito da economia americana. Talvez a pressão por mudanças rápidas não seja tão gritante para as empresas dos EEUU.

A abertura da economia coloca o Brasil com uma tecnologia 30 anos atrasada frente à tecnologia das empresas líderes mundiais. Assim, além da mudança em si para adequação às novas realidades, é necessário produzir resultados rápidos, caso contrário a empresa corre risco de não sobreviver.

A Reengenharia possui como principal característica a rapidez com que produz resultados. Sua implantação produz resultados imediatos, pois os procedimentos de trabalho são profun- 
Tabela 4 - Grau de prioridade dado aos seguintes objetivos durante o planejamento da Reengenharia.

\begin{tabular}{|l|c|c|}
\hline & Média & $\sigma$ \\
\hline 2. aumento da competitividade por redução de custos & 4,047 & 0,872 \\
\hline 4. ênfase no elemento que agrega valor às atividades & 3,884 & 0,731 \\
\hline 5. uso do tempo como uma arma para a competitividade & 3,279 & 1,076 \\
\hline 6. focalização nos objetivos e resultados finais & 4,047 & 0,925 \\
\hline 8. criação de um ambiente de mudanças & 3,674 & 1,190 \\
\hline 9. redesenho dos processos essenciais para a empresa & 3,907 & 0,947 \\
\hline 10.redução de custos e aumento de produtividade & 4,279 & 0,826 \\
\hline $\begin{array}{l}\text { 11.utilização das potencialidades da tecnologia de informação para } \\
\text { melhorar (mudar) os processos }\end{array}$ & 3,721 & 1,098 \\
\hline
\end{tabular}

Tabela 5 - Grau de atingimento dos objetivos estabelecidos no planejamento da Reengenharia.

\begin{tabular}{|l|c|c|}
\hline & Média & $\sigma$ \\
\hline 2. aumento da competitividade por redução de custos & 3,537 & 1,075 \\
\hline 4. ênfase no elemento que agrega valor às atividades & 3,366 & 0,888 \\
\hline 6. focalização nos objetivos e resultados finais & 3,659 & 0,825 \\
\hline 7. aplicação de novas tecnologias & 3,268 & 1,049 \\
\hline 8. criação de um ambiente de mudanças & 3,634 & 1,090 \\
\hline 9. redesenho dos proc. essenciais para a empresa & 3,707 & 0,873 \\
\hline 10.redução de custos e aumento de produtividade & 3,707 & 0,981 \\
\hline Média & 3,554 & 0,969 \\
\hline
\end{tabular}

damente alterados. Contudo, o novo processo pode ser melhor ou pior que o anterior.

Referindo-se ainda à Tabela 4, outra conclusão importante que se pode tirar é sobre o interesse estratégico dos processos de Reengenharia. Nota-se uma profunda tendência defensiva nos objetivos, isto é, a empresa usa esse processo para se proteger das ameaças do mercado. Não é intenção criar novas aplicações, conquistar novos mercados, lançar novos produtos. A única preocupação é tornar eficiente os processos de negócio.

Mais conclusões interessantes podem ser obtidas a partir da questão da Tabela 5. Foram listados apenas os itens com maior grau de atingimento. Nota-se que a própria média possui um valor intermediário entre o médio e o alto.

$\mathrm{Na}$ pesquisa americana, o valor médio ficou exatamente em 3 e retratou um atingimento dos objetivos menor que no Brasil. Os motivos para isso podem ser vários, dentre eles pode-se destacar a situação de maior risco, que também oferece maiores oportunidades para melhorias; o choque que a economia brasileira levou quando entrou em contato com as economias mais modernas abriu os olhos dos empresários para as oportunidades apresentadas pelas modernas técnicas de gestão de negócios. Graças a isso, as mudanças ocorreram em um grau mais elevado no Brasil. Outro motivo que pode ser válido é o grau de percepção e exigência dos gerentes brasileiros ser diferente do grau dos gerentes norte-americanos. Na pergunta da Tabela 6, tenta-se identificar os principais problemas que aparecem na implantação de um processo de Reengenharia. O resultado mostra que mudar os hábitos dos empregados, bem como a tecnologia de informação inadequada são os principais problemas apontados pelas empresas. 
Tabela 6 - Grau de dificuldade imposto pelos seguintes problemas que foram encontrados na implantação da Reengenharia.

\begin{tabular}{|l|c|c|}
\hline & Média & $\sigma$ \\
\hline 2. mudar os hábitos dos empregados & 3,488 & 0,856 \\
\hline 6. o processo de Reengenharia tornou-se maior do que o esperado & 2,952 & 0,909 \\
\hline $\begin{array}{l}\text { 7. infra-estrutura insuficiente dos Sistemas de Informação para suportar } \\
\text { a Reengenharia }\end{array}$ & 3,286 & 1,175 \\
\hline $\begin{array}{l}\text { 9. falta de delegação de recursos (fundos) para as mudanças por parte } \\
\text { da alta administração }\end{array}$ & 2,372 & 1,092 \\
\hline 19. ambiente nada indicado para a Reengenharia & 1,930 & 0,704 \\
\hline $\begin{array}{l}\text { 20.problemas de comunicação devido a barreiras criadas pelas } \\
\text { subunidades dentro da empresa }\end{array}$ & 2,762 & 1,055 \\
\hline 21. falta de empenho da alta administração & 1,884 & 0,823 \\
\hline
\end{tabular}

Tabela 7 - Grau de obtenção dos benefícios apresentados abaixo pelo processo de Reengenharia.

\begin{tabular}{|l|c|c|}
\hline & Média & $\sigma$ \\
\hline 1. utilização mais eficiente dos recursos de máquina & 3,275 & 0,784 \\
\hline 3. diminuição do tempo de ciclo, do estoque ou do custo & 3,415 & 0,836 \\
\hline 4. aumento do crescimento econômico & 3,025 & 0,800 \\
\hline 5. aumento da participação no mercado & 3,049 & 0,999 \\
\hline 11. desenvolvimento de novos processos & 3,359 & 1,038 \\
\hline 12. desenvolvimento de novos mercados & 2,821 & 0,970 \\
\hline 13. desenvolvimento do pessoal & 3,625 & 1,079 \\
\hline
\end{tabular}

Como foi a alta administração quem respondeu o questionário, nota-se que o item 21 possui um valor muito baixo. Isso retrata a influência de quem responde a pergunta.

O item 19 mostra que, na maioria dos casos, a situação da empresa é crítica e mudanças são necessárias. As empresas passam por processos dessa natureza justamente para reagir a algum problema ou para obter resultados rápidos. Isso também retrata os problemas enfrentados na adaptação das empresas ao novo ambiente a que estão sujeitas.

$\mathrm{Na}$ questão da Tabela 7, tentou-se identificar quais os principais benefícios obtidos com a Reengenharia. Foram colocados em questão os principais propósitos encontrados na literatura e constatou-se que os benefícios mais importantes foram o desenvolvimento de pessoal, o desenvolvimento de novos processos, redução do tempo de ciclo ou do estoque ou dos custos, e a utilização mais eficiente dos recursos de máquina.

Perguntou-se e foram identificadas (Tabela 8) quais as principais causas do sucesso (mesmo que parcial) na obtenção de resultados desejados. Assim como para as outras questões, nota-se uma profunda influência da situação econômica do país. Os principais agentes que motivam e fazem com que os resultados aconteçam são as pressões externas e as oportunidades de melhoria interna dos processos antigos.

Essa questão também mostra que as Reengenharias são realizadas por forças internas da organização. O auxílio de especialistas externos (consultorias; item 1) mostra-se pouco expressivo. $\mathrm{O}$ fator encontrado está situado entre médio e baixo. Isso contradiz a posição de especialistas, entre eles Hammer, de que é imprescindível o 
Tabela 8 - Grau de importância das causas do êxito (mesmo que parcial) no atingimento dos objetivos estabelecidos.

\begin{tabular}{|l|c|c|}
\hline & Média & $\sigma$ \\
\hline 1. auxílio de especialistas externos. & 2,417 & 1,199 \\
\hline 2. motivação por demandas dos clientes e pressões da competitividade & 3,857 & 0,843 \\
\hline 5. percepção da tecnologia como um habilitador e não como uma solução & 3,190 & 1,042 \\
\hline 6. desejo por melhoria de performance & 3,929 & 0,838 \\
\hline 7. partilha das informações da mudança & 3,452 & 0,832 \\
\hline $\begin{array}{l}\text { 8. uso do mapeamento de processo para identificar quais atividades não } \\
\text { agregam valor ao produto }\end{array}$ & 3,405 & 1,061 \\
\hline
\end{tabular}

Tabela 9 - Grau de importância das causas do fracasso (mesmo que parcial) no atingimento dos objetivos estabelecidos.

\begin{tabular}{|l|c|c|}
\hline & Média & $\sigma$ \\
\hline 2. mudança nos antigos hábitos dos empregados & 3,132 & 1,018 \\
\hline $\begin{array}{l}\text { 7. infra-estrutura insuficiente dos Sistemas de Informação para suportar } \\
\text { a Reengenharia }\end{array}$ & 3,053 & 1,138 \\
\hline 10. falta de empregados treinados para realizar as implementações & 2,842 & 0,973 \\
\hline $\begin{array}{l}\text { 15.problemas de comunicação devido a barreiras criadas pelas } \\
\text { subunidades dentro da empresa }\end{array}$ & 2,838 & 1,143 \\
\hline 16. falta de empenho da alta administração & 2,083 & 1,105 \\
\hline
\end{tabular}

envolvimento de consultorias nas implantações de Reengenharia de Processos de Negócio.

Para finalizar, depois de encontrar os fatores de sucesso, definem-se (Tabela 9) os fatores que atrapalharam a conquista dos objetivos planejados para a Reengenharia. Constatou-se que a principal dificuldade está nos recursos humanos (mudança nos antigos hábitos dos empregados). Mudar sempre está associado a incertezas e as pessoas ainda possuem a mentalidade de que, se as coisas estão indo bem, não se deve mudar. Além disso, os cortes causados pela racionalização dos processos criam um clima de insegurança nas pessoas e é natural que elas lutem ou ajam de modo a tentar garantir seus empregos.

\section{Conclusões}

$\mathrm{U}$ ma crítica procedente da Reengenharia discutida por CASTANHEIRA \& NETZ
(1995) e confirmada neste trabalho é que ela é utilizada como uma forma defensiva, como se o mercado fosse ameaçador e não oferecesse oportunidades para as empresas. É uma crítica bastante forte que ataca os fundamentos básicos da Reengenharia. Além disso, não há preocupação com a captação de novas receitas.

A Reengenharia mexe com as organizações. Assim, deve-se entender o que compõe uma organização para compreender melhor o que a Reengenharia pode mudar. Uma organização possui primeiramente uma cultura que é uma configuração de hipóteses assumidas (valores) que um dado grupo inventou, descobriu ou desenvolveu para lidar com problemas e que são válidas a ponto de serem repassadas às outras gerações. A Reengenharia encontra na cultura sua oportunidade de transformar a organização e ao mesmo tempo o maior obstáculo para realizar qualquer mudança. 
O outro constituinte de uma organização são os indivíduos que estão estruturados e possuem em suas cabeças a cultura da empresa. São eles que irão mudar e, conseqüentemente, o sucesso da Reengenharia dos Processos de Negócio depende deles.

O que se busca são ideologias voltadas ao consenso de que a empresa é realmente um grande sistema e cada colaborador é um elo dessa corrente. Os problemas desse grande sistema devem ser sentidos por todos, ou melhor, devem incomodar a todos. Assim, cria-se um pensamento colaborador, a fim de que a solução, mesmo que em pequenas parcelas, acabe sendo encontrada de forma conjunta.

Pode-se afirmar que a Reengenharia produz processos motivadores. Esse é um fator muito positivo, pois haverá satisfação dos executores dos processos provenientes de Reengenharia, o que valoriza bastante essa aplicação.

Dentre os habilitadores, a Tecnologia da Informação sem dúvida é o mais importante. Ela é a base para a realização da maioria das mudanças. Os outros habilitadores (por exemplo, a estrutura organizacional e a política de recursos humanos), em geral, apenas colaboram, criando ambientes favoráveis às mudanças e facilitando a implementação de novas idéias. A Tecnologia de Informação deve ser vista como um habilitador e não como uma solução por si só. Ela habilita as pessoas a repensarem os processos e não deve ser utilizada para automatizar os processos existentes que se mostraram adequados em épocas em que os objetivos da empresa eram outros.

Para finalizar, destacamos algumas conclusões específicas do trabalho relativas à implantação da Reengenharia em grandes empresas brasileiras:

(a) os setores da empresa mais atingidos pelo processo de Reengenharia são a gestão de recursos humanos, a gestão da qualidade, o projeto e desenvolvimento do produto e o setor de compras;

(b) as empresas querem e precisam mudar seus processos principalmente para reduzir custos, de modo a aumentar a produtividade e a competitividade da empresa. O grau de atingimento desses objetivos situou-se entre médio e alto;

(c) os objetivos mais atingidos com a implantação da Reengenharia foram: redesenho dos processos essenciais para a empresa, redução de custos e aumento de produtividade, focalização nos objetivos e resultados finais e criação de um ambiente de mudanças;

(d) os principais problemas enfrentados durante a implantação da Reengenharia foram mudar os hábitos dos empregados e infra-estrutura insuficiente dos Sistemas de Informação para suportar a Reengenharia;

(e) os benefícios mais importantes foram o desenvolvimento de pessoal, o desenvolvimento de novos processos, redução do tempo de ciclo ou do estoque ou dos custos. Esta pergunta tem relação com as perguntas (a) e (c). As respostas de (a), (c) e (e) são compatíveis entre si; isso é um bom indicador de que houve coerência e seriedade quando os questionários foram respondidos;

(f) as principais causas do fracasso (mesmo que parcial) no atingimento dos objetivos estabelecidos são a mudança nos antigos hábitos dos empregados e a infra-estrutura insuficiente dos Sistemas de Informação para suportar a Reengenharia. Esta pergunta tem relação com a pergunta (d). Houve completa coerência nas respostas o que é mais um indicador de que as pessoas que responderam os questionários o fizeram de forma bastante séria. Vale lembrar que é extremamente importante termos algumas perguntas que verifiquem o grau de conscientização das respostas dos questionários;

(g) os principais agentes que motivam e fazem com que resultados (êxito mesmo que parcial) aconteçam são as pressões externas e as oportunidades de melhoria interna dos processos antigos;

(h) as Reengenharias são realizadas por forças internas da organização. O auxílio de especialistas externos (consultorias) mostra-se pouco expressivo. Isso contradiz a posição de espe- 
cialistas, entre eles Hammer, de que é imprescindível o envolvimento de consultorias nas implantações de Reengenharia de Processos de Negócio.

\section{Referências Bibliográficas}

BRANDT, R. \& BYRNE, J.A.: "The Virtual Corporation". Business Week, pp.99-102, February 8,1993 ,

CASTANHEIRA, J. \& NETZ, C.: “A Reengenharia Contestada". Exame, pp.112-118, 2 de Agosto, 1995.

DAVENPORT, T. \& SHORT J.: "The New Industrial Engineering: Information Technology and Business Process Redesign". Sloan Management Review, pp.11-27, Summer 1990.

DAVENPORT, T.H.: Reengenharia de Processos. Ed. Campos, Rio de Janeiro, 1994.

GROVER, V.; TENG, J.T.C. \& FIEDLER, K.D.: "Information Technology Enabled Business Process Redesign. An Integrated Planning Framework". OMEGA, vol.21, pp.433-447, 1993.
GUIMARAES, T. \& BOND, W.: "Empirically Assessing the Impact of BPR on Manufacturing Firms". Gestão \& Produção, vol.3, n.1, pp.8-32, abril de 1996.

HAMMER, M.: “Reengineering Work: Don't Automate, Obliterate". Harvard Business Review, pp.104-112, July-August 1990.

HAMMER, M. \& CHAMPY, J.: Reengenharia Revolucionando a Empresa em função dos Clientes, da Concorrência e das Grandes Mudanças da Gerência. Ed. Campus, Rio de Janeiro, 1990.

MUCCHIELLI, R.: O Questionário na Pesquisa Psicossocial. Martins Fontes Editora Ltda., São Paulo, 1979.

SAVIANI, J.R.: Repensando as Pequenas e Médias Empresas. Ed. Pioneira, São Paulo, 1994.

\section{ASSESSMENT OF THE IMPACT OF REENGINEERING ON LARGE BRAZILIAN ENTERPRISES}

\section{Abstract}

This study analyses B.P.R. (Business Process Reengineering) processes in Brazil. It is a statistical study to reveal what is happenning in terms of the radical changes occurring in Brazilian Organizations. In general terms, the methodology that was applied is the same as that utilized in a similar study in the United States. Therefore, besides drawing interesting and important conclusions about the Brazilian situation, it was also possible to compare the main results with the North-American study.

Key words: reengineering, business reconstruction, business processes. 